\title{
Absorption of Calcium and Magnesium from Fortified Human Milk by Very Low Birth Weight Infants
}

\author{
YA-MEI LIU, PATRICIA NEAL, JUDITH ERNST, CONNIE WEAVER, KARYL RICKARD, \\ DAVID L. SMITH, AND JAMES LEMONS \\ Departments of Medicinal Chemistry and Pharmacognosy [Y.L., D.L.S.], and Foods and Nutrition [C.W.], \\ Purdue University, West Lafayette, Indiana 47907, and Departments of Pediatrics [P.N., J.L.], and Nutrition and \\ Dietetics [J.E., K.R.], Riley Hospital for Children, Indiana University Medical Center, \\ Indianapolis, Indiana 46223
}

\begin{abstract}
Absorption of calcium and magnesium endogenous to human milk, as well as calcium and magnesium added as an exogenous supplement to human milk, was determined in 9 very low birth wt infants. Human milk, intrinsically labeled with stable isotopic tracers of calcium and magnesium, was prepared by administering isotopic tracers intravenously to a lactating woman. Different isotopic tracers, which were representative of calcium and magnesium in the supplement (Enfamil Human Milk Fortifier, Mead Johnson Nutritional Div.), were added to the intrinsically labeled milk. The fortified milk, which was labeled with two calcium tracers and two magnesium tracers, was given orally to the test subjects in a single feeding. True absorption of calcium and magnesium was determined from differences between the doses of tracer ingested and the quantities of tracer excreted in the feces. Stable isotopic tracers were quantified by fast atom bombardment mass spectrometry. These results demonstrate that the fractional absorptions of calcium in the human milk and the added mineral supplement are 80 and $82 \%$, respectively. A total of $89 \%$ magnesium endogenous to human milk and $86 \%$ of magnesium derived from the mineral supplement was absorbed by the VLBW infants. (Pediatr Res 25: 496-502, 1989)
\end{abstract}

\section{Abbreviations}

VLBW, very low birth wt

FABMS, fast atom bombardment mass spectrometry

The need to better define the optimum calcium intake of VLBW infants has been discussed by Ehrenkranz et al. (1) who used a stable isotopic tracer to determine calcium absorption in premature infants. As it has been previously established with radioisotopic tracers that calcium absorption by adults is 25 to $35 \%$ (2), it is surprising to find that $84 \%$ of the dietary calcium was absorbed by preterm infants. Although VLBW infants do have an unusually high need for calcium $(3,4)$, it was also recognized that this unexpectedly high value reflects calcium

Received April 15, 1988; accepted December 1, 1988.

Correspondence to David L. Smith, Ph.D., Department of Medicinal Chemistry and Pharmacognosy, Purdue University, West Lafayette, IN 47907, or James Lemons, M.D., Department of Pediatrics, Riley Hospital for Children, Indiana University Medical Center, Indianapolis, IN 46223

Supported in part by Grants from the James Whitcomb Riley Memorial Association and the Nutritional Division of the Mead-Johnson Company. absorption from a soluble salt, and not from normal dietary sources, such as milk or formula (1). This extraordinarily high value for calcium absorption by VLBW infants is also in conflict with results reported by Barltrop et al. (5), who found that $32 \%$ of a stable isotopic tracer of calcium was absorbed by VLBW infants in a similar study.

Calcium absorption, expressed as net absorption, has been investigated extensively with traditional balance methods (6-12). Although the range of values for net absorption of calcium is large (28-74\%), results from these studies do suggest that calcium absorption by VLBW infants is elevated. Values for net calcium absorption, as determined by tranditional balance studies, do not account for intestinal secretion of calcium (i.e. endogenous fecal calcium) and are, therefore, expected to be less than the true absorption, which refers to the unidirectional passage of calcium from the intestine to the circulating system. The absorption of an isotopic tracer is a direct measure of true absorption.

The bioavailability of calcium from a specific food, such as human milk, can be determined if an isotopic tracer that is completely exchanged with calcium endogenous to milk is used to mimic the flow of calcium derived specifically from the milk. As much of the calcium endogenous to milk is chemically bonded to various milk components, it is possible that an isotopic tracer that is simply mixed with milk does not undergo complete exchange with the endogenous calcium (13). In the present study, an isotopic tracer of calcium was administered intravenously to a lactating woman, who was then used as a source of intrinsically labeled milk. Absorption of the isotopic tracer by an infant fed the intrinsically labeled milk is a direct measure of the absorption of calcium endogenous to human milk. The use of an intrinsically labeled milk is now possible because of an improved method for quantifying stable isotopic tracers of metals in biologic materials $(14,15)$.

VLBW infants are frequently given human milk to which a commercial fortifier has been added. As such fortifiers contain a significant amount of calcium (e.g. $65 \%$ of the total calcium intake by VLBW infants is derived from such supplements), it is important to know the bioavailability of supplemental calcium. This was determined by adding a second calcium tracer to the intrinsically labeled milk. Because both tracers were subjected to identical physiologic and analytic conditions, results from this investigation provide an accurate comparison of the bioavailability of calcium present in human milk and a supplement consumed with the milk.

An identical procedure has been used concurrently to determine the bioavailability of magnesium from human milk and an added magnesium supplement. Although magnesium deficiency in VLBW infants is not perceived to be as important as calcium 
deficiency, there is evidence from animal studies indicating that intake of very high levels of calcium leads to magnesium deficiency $(16,17)$. It is therefore prudent to investigate magnesium absorption by VLBW infants who receive large calcium supplements.

\section{MATERIALS AND METHODS}

Preparation of isotopically labeled human milk. Human milk was provided by a $59-\mathrm{kg}$ healthy, lactating mother who had delivered a healthy term neonate 2 mo before the study was begun. The milk was free of bacterial and viral pathogens. Serologic studies on the subject were unremarkable.

Human milk was intrinsically labeled by intravenous administration of calcium and magnesium that was highly enriched in ${ }^{42} \mathrm{Ca}\left(93.77\right.$ atom \%) and ${ }^{25} \mathrm{Mg}(98.18$ atom \%). The intravenous solution was prepared by dissolving $210 \mathrm{mg}$ of ${ }^{42} \mathrm{CaCO}_{3}$ and $1073 \mathrm{mg}$ of ${ }^{25} \mathrm{MgO}$ (Oak Ridge National Laboratories, Oak Ridge, TN) in $12 \mathrm{M} \mathrm{HCl}$. This solution was filtered, tested for pyrogens, and added to $500 \mathrm{~mL}$ of sterile saline, which was administered intravenously over a period of $3 \mathrm{~h}$. After intravenous administration of the isotopic tracers, each complete expression of milk was collected separately at approximately 5 -h intervals with an electric pump. A $100-\mu \mathrm{L}$ aliquot from each expression was analyzed for isotopic tracers of calcium and magnesium.

The intrinsically labeled milk was extrinsically labeled with different isotopes of calcium and magnesium. A total of $50 \mathrm{mg}$ of ${ }^{44} \mathrm{CaCO}_{3}$ (98.55 atom \%) and $15 \mathrm{mg}$ of ${ }^{26} \mathrm{MgO}(99.55$ atom $\%)$ were dissolved in 12-M HCl. These solutions were dried, sterilized, and added to $534 \mathrm{~mL}$ of pooled human milk obtained by combining expressions taken 12 and $21.5 \mathrm{~h}$ after tracer administration. This pool of milk was thoroughly mixed and divided into $30-\mathrm{mL}$ aliquots. Aliquots of $100 \mu \mathrm{L}$ of milk were removed from 10 of the $30-\mathrm{mL}$ aliquots to assess the homogeneity of calcium and magnesium tracers. This milk, which contained four isotopic tracers, was stored at $-5^{\circ} \mathrm{C}$ for future use.

Test subjects and clinical procedures. Ten appropriate-forgestational-age infants hospitalized in the nurseries of the Indiana University Medical Center were enrolled in this study. As some fecal material from one of the subjects was lost during handling. only results for the other nine infants will be presented. The study population is described in Table 1 . The mean wt of the infants at birth and on the $1 \mathrm{st} d$ of the study were $1382 \mathrm{~g}$ and $1485 \mathrm{~g}$, respectively. Their mean gestational and postnatal ages were $30 \mathrm{wk}$ and $24 \mathrm{~d}$, respectively. Each infant was clinically stable and receiving $150 \mathrm{~mL} / \mathrm{kg} / \mathrm{d}$ of Enfamil Premature Formula (Mead Johnson Nutritional Div., Evansville, IN). Eight of the nine infants were also receiving theophylline for apneic and/ or bradycardic episodes.

On $\mathrm{d} 1$ of the study, each infant received $25 \mathrm{mg}$ of carmine

Table 1. Description of VLBW infants participating as test subjects in this investigation

\begin{tabular}{cccccc}
$\begin{array}{c}\text { Infant } \\
\text { No. }\end{array}$ & $\begin{array}{c}\text { Birth wt } \\
(\mathrm{g})\end{array}$ & $\begin{array}{c}\text { Gestational } \\
\text { age }(w \mathrm{w})\end{array}$ & Sex & $\begin{array}{c}\text { Postnatal } \\
\text { age* }^{*}(\mathrm{~d})\end{array}$ & Wt (g) \\
\hline 1 & 1600 & 30 & $\mathrm{M}$ & 22 & 1630 \\
2 & 1150 & 29 & $\mathrm{~F}$ & 33 & 1400 \\
3 & 1758 & 28 & $\mathrm{~F}$ & 30 & 1658 \\
4 & 1020 & 28 & $\mathrm{~F}$ & 30 & 1459 \\
5 & 1260 & 30 & $\mathrm{~F}$ & 16 & 1361 \\
6 & 1360 & 31 & $\mathrm{~F}$ & 18 & 1431 \\
7 & 1490 & 30 & $\mathrm{~F}$ & 25 & 1479 \\
8 & 1440 & 30 & $\mathrm{M}$ & 15 & 1360 \\
9 & 1364 & 30 & $\mathrm{~F}$ & 25 & 1588 \\
Mean & 1382 & 30 & & 24 & 1485 \\
SD & 225 & 1 & & 7 & 114 \\
\hline
\end{tabular}

* On 11 of balance study. red, dissolved in $1.0 \mathrm{~mL}$ of sterile water, via an orogastric tube. Immediately after the carmine red was administered, the orogastric tube was replaced and each infant received $20 \mathrm{~mL} / \mathrm{kg}$ of isotopically labeled and fortified human milk. It was estimated that $20 \mathrm{~mL}$ of this isotopically labeled human milk plus fortifier would provide the infant with $19 \mathrm{mg} \mathrm{Ca} / \mathrm{kg}, 2.3 \mathrm{mg} \mathrm{Mg} / \mathrm{kg}, 16$ $\mathrm{kcal} / \mathrm{kg}, 9.0 \mathrm{mg}$ phosphorus $/ \mathrm{kg}$, and $53 \mathrm{IU}$ of vitamin $\mathrm{D} / \mathrm{kg}$. The concentrations of calcium and magnesium and the four tracers of calcium and magnesium were again determined from a 500$\mu \mathrm{l}$ aliquot of fortified milk. Syringes used to administer feedings were weighed before and after feedings to determine accurately the amount of labeled milk administered. Orogastric tubes were removed after the feeding and rinsed with deionized water. The rinse was analyzed for calcium and magnesium tracers. Enfamil Premature Formula (24 kcal/oz) was fed at a vol of $150 \mathrm{~mL} / \mathrm{kg} /$ $\mathrm{d}$ to all subjects throughout the balance period. This feeding schedule provided the following daily intakes: $120 \mathrm{kcal} / \mathrm{kg}, 140$ $\mathrm{mg} \mathrm{Ca} / \mathrm{kg}, 12.5 \mathrm{mg} \mathrm{Mg} / \mathrm{kg}, 70 \mathrm{mg} \mathrm{P} / \mathrm{kg}$, and $400 \mathrm{IU}$ of vitamin D. A total of $40 \%$ of the fat was present as medium-chain triglycerides, and $50 \%$ of the carbohydrate was lactose. At $72 \mathrm{~h}$ after the human milk feeding, a second $25-\mathrm{mg}$ dose of carmine red was administered.

All stools and urine were collected individually and without significant contamination by urine from the time of administration of the isotopically labeled human milk until the second carmine red marker was passed. Stools were collected in preweighed urine collection bags (U-Bag, Hollister, Inc., Chicago, $\mathrm{IL}$ ) and stored in the sealed bag at $-70^{\circ} \mathrm{C}$.

These protocols were approved by the Indiana UniversityPurdue University at Indianapolis Committee on Protection of Human Subjects. Permission to include each infant in the study was obtained by informed consent from the parent(s).

Quantitation of isotopic tracers. Each stool was freeze-dried, and ashed at $600^{\circ} \mathrm{C}$. Inorganic residues remaining after ashing were dissolved in $1-\mathrm{M} \mathrm{HCl}$. An aliquot of each solution was diluted with $0.5-\mathrm{M} \mathrm{HCl}$ containing $0.5 \%$ lanthanum as $\mathrm{LaCl}_{3}$ and analyzed by atomic absorption spectrophotometry to determine the total quantities of calcium and magnesium.

Another aliquot was analyzed by FABMS to determine the isotopic enrichment of each of the tracers. Calcium and magnesium were isolated by adding $1 \mathrm{~mL}$ each of a saturated solution of sodium hydroxide and sodium oxalate. Under these conditions, calcium and magnesium co-precipitate as the oxalate and hydroxide, respectively. The precipitate was dissolved in approximately $20 \mu \mathrm{L}$ of $0.5 \mathrm{M}-\mathrm{HCl}$ and analyzed with a Kratos MS-50 high resolution mass spectrometer (Kratos Analytical Instruments, Ramsey, NJ) equipped with a fast atom bombardment ion source. Approximately $1 \mu \mathrm{L}$ of the solution was applied to the probe. Calcium isotopic enrichments were determined by measuring the intensities of the two tracer isotopes $\left({ }^{42} \mathrm{Ca}\right.$ and $\left.{ }^{44} \mathrm{Ca}\right)$ and a reference isotope $\left({ }^{40} \mathrm{Ca}\right)$. High precision was obtained by making multiple measurements of each beam. Identical conditions were used to record ion abundances of reference samples, which had a natural abundance of isotopes, and isotopically enriched samples. The reference could be a milk sample taken before administration of tracers to the lactating woman, or a fecal sample taken before administration of the isotopically labeled milk to the infants. The same procedure was used to determine ion abundances of magnesium tracers $\left({ }^{25} \mathrm{Mg}\right.$ and $\left.{ }^{26} \mathrm{Mg}\right)$ and the magnesium reference isotope $\left({ }^{24} \mathrm{Mg}\right)$. Ion abundance ratios $(42 / 40,44 / 40,25 / 24$, and $26 / 24)$ were determined from these data and used to calculate isotopic abundances. Methods used to quantify the stable isotopic tracers of calcium and magnesium are described in more detail in the Appendix. The instrumentation and methods have been described in detail elsewhere $(14,15)$. As the reference samples were taken before administering the tracers, they have a natural abundance of isotopes. None of the test subjects had received isotopic tracers of calcium or magnesium before this investigation. Accepted values for natural abundances of isotopes of calcium and mag- 
nesium are listed in Table 2. The total calcium or magnesium was determined by atomic absorption spectrophotometry.

Calculation of calcium and magnesium absorption. The fractional absorption of calcium and magnesium was determined from the difference between the quantities of tracer ingested and excreted in the feces. This method has been used extensively with radio tracers to determine absorption of calcium in adults (18). It has also been used with stable isotopic tracers to determine calcium absorption by infants $(1,5,19)$. The procedure is expressed analytically by equation 1 :

$$
\text { Fractional Absorption }=\alpha=\left(\text { DOSE }-\Sigma T_{\mathrm{F}}\right) / \mathrm{DOSE}
$$

where DOSE is the quantity of tracer administered to the test subject, and $T_{F}$ is the quantity of tracer excreted in the feces.

\section{RESULTS}

Characterization of labeled milk. Intrinsically labeled milk was collected from the lactating woman for $46 \mathrm{~h}$ after intravenous administration of isotopic tracers ${ }^{42} \mathrm{Ca}$ and ${ }^{25} \mathrm{Mg}$. The milk from both breasts was combined at the end of each collection period, and an aliquot was analyzed for isotopic tracers. The levels of calcium and magnesium tracers in the milk, expressed as enrichments, are plotted versus the time after tracer administration in Figure 1. Tracer enrichment in the milk collected $2.5 \mathrm{~h}$ after tracer administration is low ( $77 \%$ for ${ }^{42} \mathrm{Ca}$ and $13 \%$ for ${ }^{25} \mathrm{Mg}$ ), reflecting the time required for the tracers to pass from the blood stream to the milk. Although the level of calcium tracer reached a maximum approximately $12 \mathrm{~h}$ after tracer administration, the level of the magnesium tracer did not reach a maximum until $22 \mathrm{~h}$ postinfusion.

Milk collected at 12 and $21.5 \mathrm{~h}$ after administration of the tracers was combined to form a single pool that would be used for the entire study. After addition of the extrinsic tracers, the milk was thoroughly mixed and subdivided into aliquots for storage. Ten of these aliquots were analyzed for calcium and magnesium. The concentrations of calcium and magnesium (i.e. all isotopes) were 8.31 and $2.48 \mu \mathrm{M} / \mathrm{mL}$, respectively. The en-

Table 2. Masses and natural abundances of isotopic tracers used in this study

\begin{tabular}{ccl}
\hline Isotope & $\mathrm{NA}^{*}$ & \multicolumn{1}{c}{ Use } \\
\hline${ }^{40} \mathrm{Ca}$ & 96.95 & Internal standard \\
${ }^{44} \mathrm{Ca}$ & 2.083 & Extrinsic tracer \\
${ }^{42} \mathrm{Ca}$ & 0.646 & Intrinsic tracer \\
${ }^{24} \mathrm{Mg}$ & 78.70 & Internal standard \\
${ }^{26} \mathrm{Mg}$ & 11.17 & Extrinsic tracer \\
${ }^{25} \mathrm{Mg}$ & 10.13 & Intrinsic tracer \\
\hline
\end{tabular}

* Natural abundance expressed as atom \%

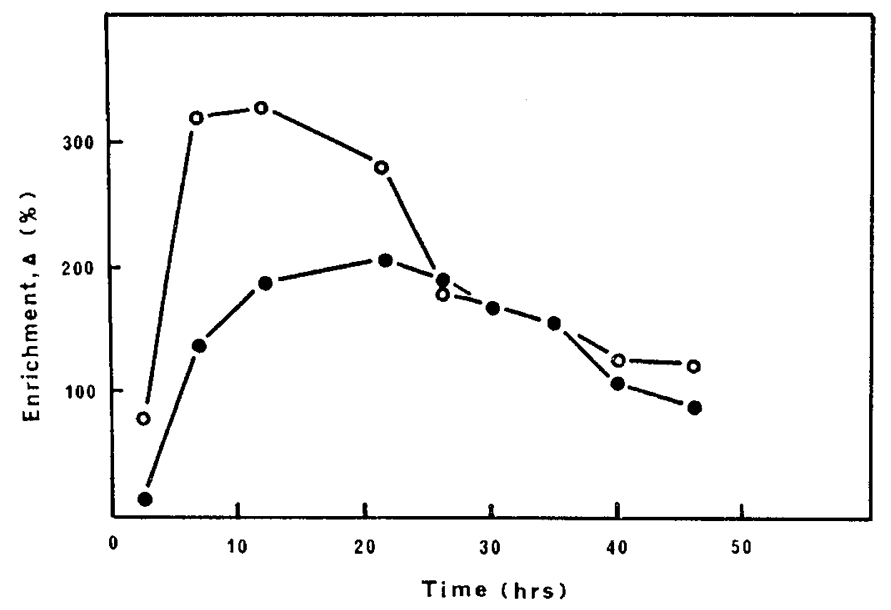

Fig. 1. Isotopic enrichments, $\Delta$, of intrinsic tracers ${ }^{25} \mathrm{Mg}(\bullet)$ and ${ }^{42} \mathrm{Ca}$ (O) in human milk vs. time after intravenous tracer administration. richments, $\Delta$, of the four tracers were measured for each of the aliquots to determine the homogeneity of the tracers in the milk. Although not equal to the tracer concentration, the enrichment is directly related to the tracer concentration, as indicated in the Appendix. The mean enrichment values, given in Table 3, ranged from $174 \%$ for ${ }^{25} \mathrm{Mg}$ to $565 \%$ for ${ }^{44} \mathrm{Ca}$. The coefficients of variation of the enrichments of ${ }^{44} \mathrm{Ca}$ and ${ }^{26} \mathrm{Mg}$ for the 10 aliquots are $1.2 \%$ and $0.7 \%$, respectively, indicating that the extrinsic tracers were uniformly distributed in the milk. The concentrations of the four tracers (see Table 3) were calculated from these data using equations 10 or 11 in the Appendix. These concentrations were used to determine the tracer doses administered to the test subjects.

Absorption of calcium and magnesium. The effect of tracer secretion from the circulating system to the intestine was minimized by analyzing the stools individually for the four isotopic tracers. The magnitude of the effect of tracer secretion on the determination of absorption is indicated by results in Figure 2, which is a plot of the cumulative tracer excretion in the feces versus time for two subjects. Upon reaching a plateau, the cumulative fecal tracer excretion continues to increase slightly because some of the absorbed tracer is being returned to the intestinal tract. The error in the measured value for absorption that is due to intestinal secretion of tracer can be determined by extrapolating a line drawn through the plateau of each curve to the $y$ axis. These results show that this correction would decrease the values for absorption by approximately $2 \%$. As this correction is much smaller than intersubject variability $(10 \%)$ and as it will change absorption values for all tracers by the same amount, it was neglected. Secretion of an oral tracer into the intestine is minimal because the tracer is diluted by the exchangeable pool of calcium. Ehrenkranz et al. (1) adopted a similar approach for their investigation of calcium absorption by VLBW infants. The data in Figure 2 also show that the time required for excretion of the tracer is variable, but usually complete within $50 \mathrm{~h}$ after tracer administration.

Absorption of isotopic tracers of calcium and magnesium was determined from the quantities of tracer excreted in the feces using equation 1. Results for tracer absorption by the nine infants, as well as the means and the standard deviations, are given in Table 4.

\section{DISCUSSION}

Results in Table 4 show that $82 \%$ (range $62-93 \%$ ) of the extrinsic tracer of calcium was absorbed by the VLBW infants in this study. Correlation of these results with previous investigations in which stable isotopes were used as extrinsic tracers of calcium is indicated by the compilation in Table 5 . The present value of $82 \%$ is in good agreement with Ehrenkranz et al. (1), who found that $84 \%$ of the extrinsic label was absorbed. Although their results suggest that calcium absorption from preterm milk,

Table 3. Concentrations and enrichments of isotopic tracers of calcium and magnesium in the fortified milk used in this investigation

\begin{tabular}{lcccc}
\hline & ${ }^{42} \mathrm{Ca}$ & ${ }^{44} \mathrm{Ca}$ & ${ }^{25} \mathrm{Mg}$ & ${ }^{26} \mathrm{Mg}$ \\
\hline $\begin{array}{l}\text { Tracer enrichment, } \\
\quad \Delta(\%)\end{array}$ & & & & \\
$\quad$ Mean & 315 & 565 & 174 & 454 \\
CV \% & 0.8 & 1.2 & 0.5 & 0.7 \\
$\begin{array}{l}\text { Tracer } \\
\begin{array}{l}\text { Concentration } \\
(\mu \mathrm{M} / \mathrm{mL})^{*}\end{array}\end{array}$ & 0.166 & 0.949 & 0.587 & 1.406 \\
\hline
\end{tabular}

* Because the tracer enrichments are very large, slightly different form of equation 2, which accounts for the fact that the tracer makes significant contribution to the total amount of calcium or magnesium, has been used to calculate the concentration of isotopic tracer. 


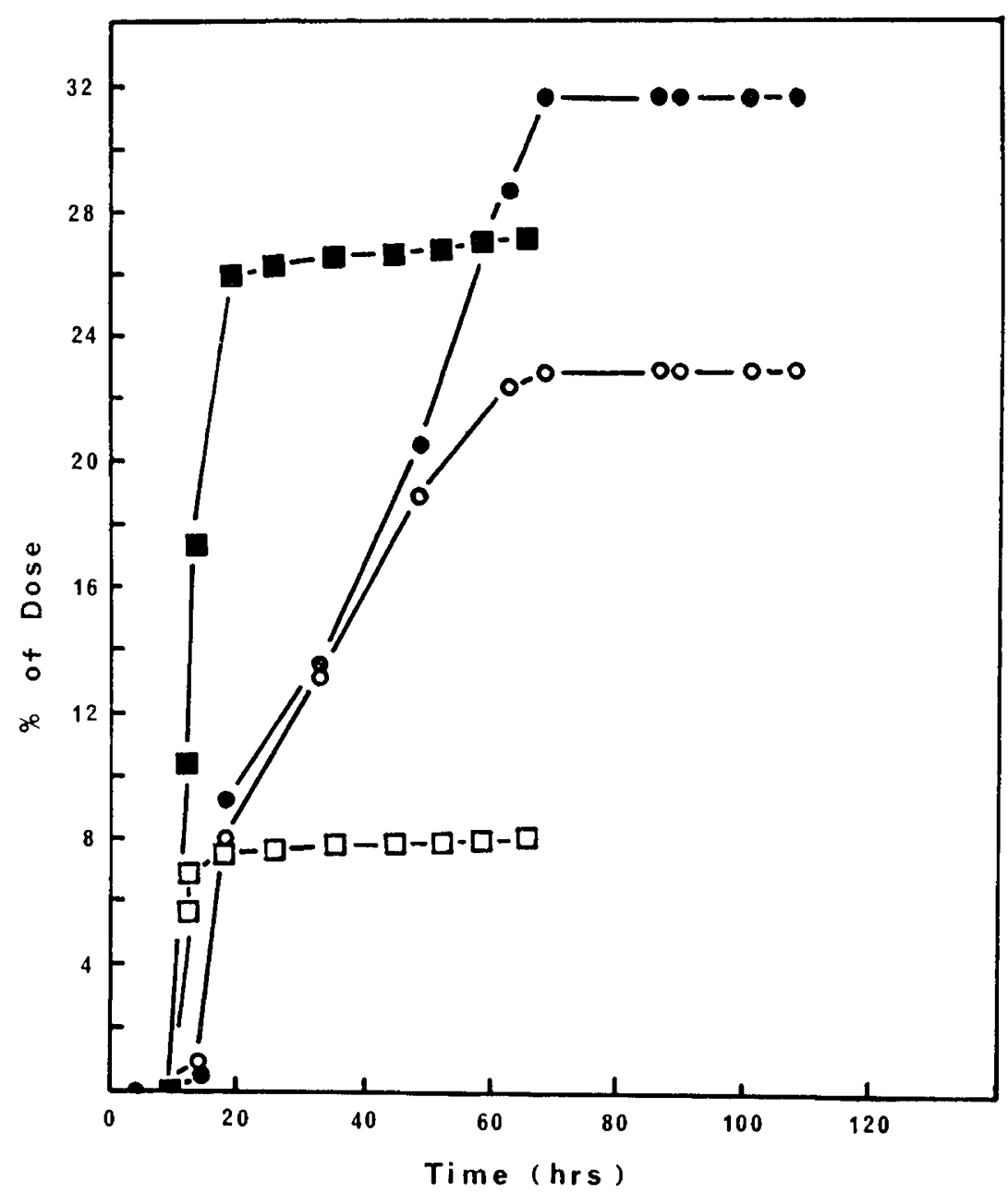

Fig. 2. Cumulative excretion of ${ }^{44} \mathrm{Ca}(\mathrm{O}, \square)$ and ${ }^{26} \mathrm{Mg}(\boldsymbol{\bullet}, \mathbf{\square})$ in the feces of two infants $v$ s. time after tracer administration

Table 4. Absorption of extrinsic and intrinsic isotopic tracers of calcium and magnesium

\begin{tabular}{cccccc} 
& \multicolumn{2}{c}{ Calcium absorption } & & \multicolumn{2}{c}{$\begin{array}{c}\text { Magnesium } \\
\text { Infant } \\
\text { Nosorption }\end{array}$} \\
\cline { 2 - 3 } \cline { 5 - 6 } & Extrinsic & Intrinsic & & Extrinsic & Intrinsic \\
\hline 1 & 85 & 84 & & 90 & 91 \\
2 & 87 & 85 & 89 & 92 \\
3 & 80 & 80 & 88 & 90 \\
4 & 93 & 92 & 86 & 90 \\
5 & 79 & 78 & 83 & 87 \\
6 & 85 & 83 & 91 & 93 \\
7 & 86 & 84 & 89 & 91 \\
8 & 62 & 61 & 75 & 78 \\
9 & 80 & 77 & 84 & 86 \\
Average & 82 & 80 & 86 & 89 \\
SD & 9 & 9 & 5 & 5 \\
\hline
\end{tabular}

fortified preterm milk, and premature formula (range $81-90 \%$ ) is not the same, the differences were not statistically significant. Their results for the bioavailability of calcium from different sources suggest that the variation of fractional absorption with diet by VLBW infants is likely less than $10 \%$.

Barltrop et al. (5) also concluded that absorption of calcium (i.e. an extrinsic tracer) by VLBW infants is independent of calcium intake. However, they report that only $32 \%$ of the calcium tracer is absorbed. This is substantially less than reported in the Ehrenkranz study ( $84 \%)$ and the present investigation $(82 \%)$. It is noted that the test subjects in the Barltrop study had lower postnatal ages and higher gestational ages. Moore et al.
Table 5. Compilation of data from the present and previous investigations of absorption of an extrinsic isotopic tracer of calcium by VLBW infants $(1,5,19)$

\begin{tabular}{lcccc} 
& Ref. 1 & Ref. 5 & Ref. 19 & $\begin{array}{c}\text { Present } \\
\text { study }\end{array}$ \\
\hline $\begin{array}{l}\text { Fractional ab- } \\
\quad \text { Sorption }\end{array}$ & 84 & 32 & 41,86 & 82 \\
$\begin{array}{l}\text { Ca intake } \\
\quad(\mathrm{mg} / \mathrm{kg} / \mathrm{d})\end{array}$ & $44-143^{*}$ & $100-229 \dagger$ & 135,107 & 143 \\
$\begin{array}{l}\text { Ca absorption } \\
\quad(\mathrm{mg} / \mathrm{kg} / \mathrm{d}) \ddagger\end{array}$ & $40-118^{*}$ & $43-161 \dagger$ & 55,93 & 117 \\
$\begin{array}{l}\text { No. of subjects } \\
\text { Postnatal age (d) }\end{array}$ & 13 & 10 & 2 & 9 \\
$\begin{array}{l}\text { Birth age (wk) } \\
\text { Birth wt }(\mathrm{kg})\end{array}$ & 29 & 15 & 30,59 & 24 \\
\hline
\end{tabular}

* Results are the range of the means for three groups of infants given a premature formula, preterm human milk, and fortified preterm human milk.

$\dagger$ Results are ranges of the absolute data for three groups of infants given cows' milk formulas, which differed in $\mathrm{Ca} / \mathrm{P}(0.56,1.4$, and 2.4$)$.

$\ddagger$ Results are calculated from the fractional absorption of the isotopic tracer and the calcium intake.

(19), the only other group to use isotopic tracers to investigate calcium absorption in infants, reported that $41 \%$ and $86 \%$ of an extrinsic tracer was absorbed by a study group of two infants.

An important goal of this investigation was to determine whether absorption of an extrinsic tracer of calcium is the same as absorption of calcium endogenous to human milk. Fransson 
et al. (20) have shown that $37 \%$ of calcium in human milk is in the low mol wt portion. The bioavailability of this calcium can likely be determined with an extrinsic tracer because it is expected to undergo complete exchange with the isotopic tracer. However, an additional $44 \%$ of the calcium in human milk is bound to the protein (20) and may not undergo exchange with an extrinsic tracer (13).

The present investigation has validated the extrinsic tracer method for human milk by comparing the absorption of extrinsic and intrinsic tracers. Milk was intrinsically labeled by administering an isotopic tracer $\left({ }^{42} \mathrm{Ca}\right)$ intravenously to a lactating woman. This tracer was rapidly dispersed in her exchangeable calcium pool (21) and subsequently incorporated in her milk. As the intrinsic tracer is mixed with calcium in the exchangeable pool before its incorporation into the milk, it is chemically and biologically indistinguishable from calcium normally present in human milk. Absorption of this tracer is, therefore, a direct measure of the bioavailability of calcium endogenous to human milk. Results in Table 4 show that $80 \%$ of the intrinsically labeled calcium tracer was absorbed. This is not statistically different from absorption of the extrinsic tracer ( $82 \%)$. It follows that extrinsic tracers of calcium likely undergo complete exchange with calcium endogenous to human milk, and that future investigations of calcium absorption from human milk can be made with extrinsic tracers. It is noted that a larger portion of the calcium in bovine milk is bound to casein and, therefore, may not undergo isotopic exchange as readily (13).

As the present investigation has demonstrated that the absorption of extrinsic tracers of calcium is an accurate measure of the bioavailability of calcium endogenous to human milk, results from previous tracer studies can be compared in a meaningful way with results obtained through traditional balance studies. A wide range of values have been obtained with the balance method. However, if only those investigations which used human milk fortified with calcium and vitamin $\mathrm{D}$ are considered, most report net absorption of approximately $65 \%(7,9,10)$. As this composite value for net absorption will be increased when adjusted for intestinal excretion of calcium, results from balance studies support the high levels for true absorption found by Ehrenkranz et al. (1) and in the present study. The only direct determination of intestinal excretion of calcium by infants has been reported by Moore et al. (19). If the composite value for net absorption were corrected for intestinal excretion (19), it increases to $80 \%$, which is in good agreement with the present value for true absorption of calcium by VLBW infants.

True absorption of magnesium from fortified human milk, labeled with both an extrinsic and an intrinsic isotopic tracer, were also determined in the present investigation. Results presented in Table 4 show that $86 \%$ (range $75-91 \%$ ) of the extrinsic tracer was absorbed, and $89 \%$ (range $78-93 \%$ ) of the intrinsic tracer was absorbed. A paired $t$ test of these results indicates that the difference in absorption of magnesium from these two sources is not statistically significant. As in the case of calcium tracers described above, these results indicate that isotopic tracers of magnesium undergo complete equilibration with magnesium endogenous to human milk. This conclusion is in agreement with Schwartz et al. (22), who used intrinsically and extrinsically labeled vegetables and concluded that the corresponding tracers of magnesium are absorbed with equal efficiency by adults. Results from these two studies suggest that the tendency of an extrinsic tracer to undergo exchange with endogenous magnesium may be efficient for many foods. Previous investigations, which used radio-isotopic tracers, have shown that magnesium absorption by adults is approximately $50 \%(23,24)$. Hence, as in the case of calcium, VLBW infants absorb magnesium with a much higher efficiency than adults.

Limited information describing absorption of dietary magnesium by VLBW infants has been published. Schanler et al. (10) found that $57 \%$ of magnesium in human milk fortified with skim and cream portions of mature human milk was absorbed.
Other investigations (25-27) have reported that $55 \%$ to $75 \%$ of ingested magnesium is absorbed by normal infants. As intestinal secretion of magnesium by infants is not known, a quantitative comparison of these results for net absorption with present values for true absorption cannot be made. Magnesium absorption by infants has not been previously investigated using isotopic tracers.

Isotopic tracers of calcium and magnesium have been quantified in this investigation by high resolution FABMS $(14,15)$. This method has proven especially suited for the present study because isotopic enrichments of the intrinsic labels were necessarily low and because only minimal sample preparation was required. In addition, the measurements can be made on any high resolution mass spectrometer equipped with a fast atom bombardment ion source. Quantitation of isotopic tracers of metals by FABMS has recently been extended to zinc (28) and iron (29).

Standard deviations (5-9\%) for fractional absorption given in Table 4 are due to a combination of intersubject variability and the precision of the analytic methods. Consideration of possible errors in the determination of total calcium, isotopic enrichments, and the quantity of tracer administered, suggests that the uncertainty of fractional absorption due to uncertainty in analytic measurements is likely less than $5 \%$. However, the absorption of two tracers of the same element depends only on the corresponding doses and the enrichments, and is independent of the total quantity of that element (i.e. the atomic absorption measurement) as well as errors resulting from fecal loss. As the enrichments of intrinsic and extrinsic tracer isotopes are determined simultaneously, the uncertainty in the difference in their enrichments is very low. It follows that, although the uncertainty in the absolute values of fractional absorption may be as large as $5 \%$, the uncertainty in the relative absorption of two tracers of the same element is less.

This investigation has demonstrated that calcium endogenous to human milk, as well as calcium added as a supplement to human milk, are absorbed by VLBW infants with equal efficiency. A similar observation was made for magnesium. These results also show that true calcium and magnesium absorption by VLBW infants is much greater than in adults. Despite the high levels of calcium intake, magnesium deficiency is unlikely because it is still absorbed with a high efficiency. As the extrinsic tracers of calcium and magnesium were absorbed as though they were endogenous to the milk, future investigations designed to determine effects of calcium, phosphorus, or vitamin D supplementation can be performed with an extrinsic tracer.

\section{REFERENCES}

1. Ehrenkranz RA, Ackerman BA, Nelli CM, Janghorbani M 1985 Absorption of calcium in premature infants as measured with a stable isotope ${ }^{46} \mathrm{Ca}$ extrinsic tag. Pediatr Res 19:178-184

2. Heaney RP, Recker RR 1985 Estimation of true calcium absorption. Ann Intern Med 103:516-521

3. Amer Acad Ped 1978 Calcium requirements in infancy and childhood. Pediatrics 62:826-834

4. Atkinson SA 1983 Calcium and phosphorus requirements of low birth weight infants: a nutritional and endocrinological perspective. Nutr Rev 41:69-77

5. Barltrop D, Mole RH, Sutton A 1977 Absorption and endogenous faecal excretion of calcium by low birthweight infants on feeds with varying contents of calcium and phosphate. Arch Dis Child 52:41-49

6. Huston RK, Reynolds JW, Jensen C, Buist NRM 1983 Nutrient and mineral retention and vitamin $\mathrm{D}$ absorption in low-birth-weight infants: effect of medium-chain triglycerides. Pediatrics 72:44-48

7. Shaw JCL 1976 Evidence for defective skeletal mineralization in low-birthweight infants: the absorption of calcium and fat. Pediatrics 57:16-25

8. Shenai JP, Reynolds JW, Babson SG 1980 Nutritional balance studies in verylow-birth-weight infants: enhanced nutrient retention rates by an experimental formula. Pediatrics 66:233-238

9. Senterre J, Putet G, Salle B, Rigo J 1983 Effects of vitamin D and phosphorus supplementation on calcium retention in preterm infants fed banked human milk. J Pediatr 305-307

10. Sachnler RJ, Garza C, O'Brian Smith E 1985 Fortified mothers' milk for very low birth weight infants: results of macromineral balance studies. J Pediatr 107:767-774 
11. Tantibhedhyangkul P, Hashim SA 1978 Medium-chain triglyceride feeding in premature infants: effects on calcium and magnesium absorption. Pediatrics 61:537-545

12. Williams ML, Rose CS, Morrow G III, Sloan SE, Barness LA 1970 Calcium and fat absorption in neonatal period. Am J Clin Nutr 23:1322-1330

13. Yamauchi K, Yoneda Y 1977 Effect of some treatments of milk on the exchangeability of colloidal calcium in milk with soluble calcium. Agric Biol Chem 41:2395-2399

14. Smith DL 1983 Determination of stable isotopes of calcium in biological fluids by fast atom bombardment mass spectrometry. Anal Chem 55:2391-2393

15. Jiang X, Smith DL 1987 Quantitation of stable isotopic tracers of calcium by fast atom bombardment mass spectrometry. Anal Chem 59:2570-2574

16. McCarron DA, Lucas PA, Shneidman RJ, LaCour B, Drueke T 1985 Blood pressure development of the spontaneously hypertensive rat after concurrent manipulations of dietary $\mathrm{Ca}^{2+}$ and $\mathrm{Na}^{+}$J Clin Invest 76:1147-1154

17. Hardwich LH, Clemens RA, Jones MR 1987 Effects of calcium phosphate supplementation on calcium, phosphorus, and magnesium metabolism in the wistar rat. Nutr Res 7:787-796

18. Allen LH 1982 Calcium bioavailability and absorption: a review. Am J Clin Nutr 35:783-808

19. Moore LJ, Machlan LA, Lim MO, Yergey AL, Hansen JW 1985 Dynamics of calcium metabolism in infancy and childhood. I. Methodology and quantification in the infant. Pediatr Res 19:329-334

20. Fransson G-B, Lonnerdal B 1982 Zinc, copper, calcium, and magnesium in human milk. J Pediatr 101:504-508

21. Neer R, Berman M, Fisher L, Rosenberg LE 1967 Multicompartmental analysis of calcium kinetics in normal adult males. J Clin Invest 46:1364 1379

22. Schwartz R, Spencer H, Jones Welsh J 1984 Magnesium absorption in human subjects from leafy vegetables, intrinsically labeled with stable ${ }^{26} \mathrm{Mg}$. Am J Clin Nutr 39:571-776

23. Avioli LV, Berman M $1966 \mathrm{Mg}^{28}$ kinetics in man. J Appl Physiol 21:16881694

24. Schwartz R, Spencer H, Wentworth RA 1978 Measurement of magnesium absorption in man using stable ${ }^{26} \mathrm{Mg}$ as a tracer. Clin Chim Acta 87:265273

25. Skyberg D, Stromme JH, Nesbakken R, Harnaes K 1968 Neonatal hypomagnesemia with selective malabsorption of magnesium-a clinical entity. Scand $\mathrm{J}$ Clin Lab Invest 21:355

26. Strome JH, Nesbakken R, Normann T, Skjorten F, Skyberg D, Johannesen B 1969 Familial hypomagnesemia. Acta Paediatr Scand 58:433

27. Slater JE 1961 Retention of nitrogen and minerals by babies 1 week old. Br J Nutr 15:83

28. Peirce PL, Hambidge KM, Goss CH, Miller LV, Fennessey PV 1987 Fast atom bombardment mass spectrometry for the determination of zinc stable isotopes in biological samples. Anal Chem 59:2034-2037

29. Eagles J, Fairweather-Tait SJ, Self R 1985 Stable isotope ratio mass spectrometry for iron bioavailability studies. Anal Chem 57:469-471

\section{APPENDIX}

The concentration of a stable isotopic tracer must be determined from differences in the concentrations of the tracer isotope in samples obtained before and after tracer administration because the stable isotope used as a tracer is usually already present as a normal component of the test subject. These differences in isotopic composition can be accurately quantified by several different mass spectrometric methods. Highest precision is achieved in all methods when the tracer isotope signal is measured relative to the signal of a second isotope, the internal standard. If this measurement is made for a sample obtained before (base sample) and after tracer administration (enriched sample), the difference in the relative signal intensities of the tracer isotope in the two samples can be used to determine the concentration of the tracer. The procedure used to determine tracer concentration in the current investigation is described below, using ${ }^{24} \mathrm{Mg}$ and ${ }^{25} \mathrm{Mg}$ as the internal standard and tracer isotopes, respectively. The concentration of isotopes will be expressed in units of $\mathrm{mol} / \mathrm{unit} \mathrm{vol}$, as absorption expressed in units of mol is the same for all isotopes. This is not true if units of mass are used.

The concentration of tracer isotope in the enriched sample, $\left.\left[{ }^{25} \mathrm{Mg}\right]\right]_{\text {Tracer, }}^{\mathrm{E}}$, is given by equation 1 , where $\left[{ }^{25} \mathrm{Mg}\right]_{\text {Endogenous }}^{\mathrm{E}}$ refers to ${ }^{25} \mathrm{Mg}$ that is already present in the test subject, and $\left[{ }^{25} \mathrm{Mg}\right]^{\mathrm{E}}$ refers to ${ }^{25} \mathrm{Mg}$ derived from both sources. The mass spectrometer signal, $\mathrm{I}_{\mathrm{i}}$, for isotope

$$
\left[{ }^{25} \mathrm{Mg}\right]_{\text {Tracer }}^{\mathrm{E}}=\left[{ }^{25} \mathrm{Mg}\right]^{\mathrm{E}}-\left[{ }^{25} \mathrm{Mg}\right]_{\text {Endogenous }}^{\mathrm{E}}
$$

$\mathrm{i}$ in for the base (B) and enriched (E) samples are related to the molar concentrations of the isotopes by the following expression:

$$
\begin{aligned}
& \mathrm{R}^{\mathrm{E}}=\left(\mathrm{I}_{25} / \mathrm{I}_{24}\right)^{\mathrm{E}}=\alpha\left[{ }^{25} \mathrm{Mg}\right]^{\mathrm{E}} /\left[^{24} \mathrm{Mg}\right]^{\mathrm{E}} \\
& \mathrm{R}^{\mathrm{B}}=\left(\mathrm{I}_{25} / \mathrm{I}_{24}\right)^{\mathrm{B}}=\alpha\left[{ }^{25} \mathrm{Mg}\right]^{\mathrm{B}} /\left[^{24} \mathrm{Mg}\right]^{\mathrm{B}}
\end{aligned}
$$

where $\alpha$ is a proportionality constant. If both samples are analyzed under the same conditions, $\alpha$ will be the same. Dividing $\mathrm{R}^{\mathrm{E}}$ by $\mathrm{R}^{\mathrm{B}}$ and solving for $\left[{ }^{25} \mathrm{Mg}\right]^{\mathrm{E}}$ gives the following expression:

$$
\left[{ }^{25} \mathrm{Mg}\right]^{\mathrm{E}}=\left[\frac{\mathrm{R}^{\mathrm{E}}}{\mathrm{R}^{\mathrm{B}}}\right]\left(\frac{\left[{ }^{25} \mathrm{Mg}\right]^{\mathrm{B}}\left[{ }^{24} \mathrm{Mg}\right]^{\mathrm{E}}}{\left.{ }^{24} \mathrm{Mg}\right]^{\mathrm{B}}}\right)
$$

Let $\mathrm{f}_{24}^{\mathrm{B}}, \mathrm{f}_{25}^{\mathrm{B}}, \mathrm{f}_{24}^{\mathrm{E}}$, etc. be the fractional atomic abundance of an isotope in the base (B) or enriched $(\mathrm{E})$ sample such that

$$
\left[{ }^{25} \mathrm{Mg}\right]^{\mathrm{B}}=\mathrm{f}_{25}^{\mathrm{B}}[\mathrm{Mg}]^{\mathrm{B}}
$$

where $[\mathrm{Mg}]^{\mathrm{B}}$ is the concentration of magnesium in the base sample. A similar expression described the concentration of each isotope in the enriched and the base samples. Substituting this notation into equation 4 for $\left[{ }^{25} \mathrm{Mg}\right]^{\mathrm{B}},\left[{ }^{24} \mathrm{Mg}\right]^{\mathrm{E}}$, and $\left[{ }^{24} \mathrm{Mg}\right]^{\mathrm{B}}$, followed by canceling $[\mathrm{Mg}]^{\mathrm{B}}$, gives the following expression:

$$
\left[{ }^{25} \mathrm{Mg}\right]^{\mathrm{E}}=\left(\frac{\mathrm{R}^{\mathrm{E}}}{\mathrm{R}^{\mathrm{B}}}\right)\left(\frac{\mathrm{f}_{25}^{\mathrm{B}} \mathrm{f}_{24}^{\mathrm{E}}[\mathrm{Mg}]^{\mathrm{E}}}{\mathrm{f}_{24}^{\mathrm{B}}}\right)
$$

Substituting this expression for $\left[{ }^{25} \mathrm{Mg}\right]^{\mathrm{E}}$ in equation 1 gives the following equation:

$$
\left[{ }^{25} \mathrm{Mg}\right]_{\text {Tracer }}^{\mathrm{E}}=\left(\frac{\mathrm{R}^{\mathrm{E}}}{\mathrm{R}^{\mathrm{B}}}\right)\left(\frac{\mathrm{f}_{25}^{\mathrm{B}} \mathrm{f}_{24}^{\mathrm{E}}[\mathrm{Mg}]^{\mathrm{E}}}{\mathrm{f}_{24}^{\mathrm{B}}}\right)-\left[{ }^{25} \mathrm{Mg}\right]_{\text {Endogenous }}^{\mathrm{E}}
$$

The concentration of ${ }^{25} \mathrm{Mg}$ that is endogenous to the sample (i.e. excluding ${ }^{25} \mathrm{Mg}_{\text {Tracer }}$ ) is given by equation 8 :

$$
\left[{ }^{25} \mathrm{Mg}\right]_{\text {Endogenous }}^{\mathrm{E}}=\mathrm{f}_{25}^{\mathrm{B}}[\mathrm{Mg}]^{\mathrm{E}}-\left[{ }^{25} \mathrm{Mg}\right]_{\text {Tracer }}^{\mathrm{E}}
$$

The only remaining unknown quantity in equation 7 is $\mathrm{f}_{24}^{\mathrm{E}}$, which is given by equation 9 .

$$
\mathrm{f}_{24}^{\mathrm{E}}=\frac{\mathrm{f}_{24}^{\mathrm{B}}[\mathrm{Mg}]^{\mathrm{E}}-\left[{ }^{25} \mathrm{Mg}\right]_{\text {Tracer }}^{\mathrm{E}}}{[\mathrm{Mg}]^{\mathrm{E}}}
$$

Substituting the expressions in equations 8 and 9 for $\left[{ }^{25} \mathrm{Mg}\right]_{\text {Endogenous }}^{\mathrm{E}}$ and $\mathrm{f}_{24}^{\mathrm{f}}$ in equation 7 gives equation 10 , from which the concentration of tracer, $\left.\left[{ }^{25} \mathrm{Mg}\right]\right]_{\text {racer }}^{\mathrm{E}}$ can be calculated. This expression, which was used to determine the concentration of ${ }^{25} \mathrm{Mg}$ and ${ }^{26} \mathrm{Mg}$ in the present study, may be used to quantify stable isotopic tracers of any element. If the isotopic distribution in the base sample is not natural, it will be necessary to change $\mathrm{f}_{25}^{\mathrm{B}}$.

$$
\left[{ }^{25} \mathrm{Mg}\right]_{\text {Tracer }}^{\mathrm{E}}=\frac{\left(\mathrm{R}^{\mathrm{E}}-\mathrm{R}^{\mathrm{B}}\right) \mathrm{f}_{25}^{\mathrm{B}}[\mathrm{Mg}]^{\mathrm{E}}}{\mathrm{R}^{\mathrm{B}}-\mathrm{R}^{\mathrm{B}} \mathrm{f}_{25}^{\mathrm{B}}+\mathrm{R}^{\mathrm{E}} \mathrm{f}_{25}^{\mathrm{B}}}
$$

It is noted that equation 10 reduces to a simplified form, equation 11 , when the fractional atomic abundance of the tracer isotope, as well as the enrichment of this isotope is very small.

Appendix Table. Concentrations and fractional atomic abundance of the magnesium isotopes in a base sample (natural abundance) and an enriched sample in which the concentration of ${ }^{25} \mathrm{Mg}$ is doubled

\begin{tabular}{ccc}
\hline & \multicolumn{2}{c}{ Concentration (mmol/liter) } \\
\cline { 2 - 3 } & Base & Enriched \\
\hline$[\mathrm{Mg}]$ & 1.0000 & 1.1013 \\
{$\left[{ }^{24} \mathrm{Mg}\right]$} & 0.7870 & 0.7870 \\
$\mathrm{f}_{24}$ & 0.7870 & 0.7146 \\
{$\left[{ }^{25} \mathrm{Mg}\right]$} & 0.1013 & 0.2026 \\
$\mathrm{f}_{25}$ & 0.1013 & 0.1840 \\
{$\left[{ }^{26} \mathrm{Mg}\right]$} & 0.1117 & 0.1117 \\
$\mathrm{f}_{26}$ & 0.1117 & 0.1014 \\
\hline
\end{tabular}


For example, in the present investigation, equation 11 was used to quantify ${ }^{42} \mathrm{Ca}$ because the natural abundance of ${ }^{42} \mathrm{Ca}$ is very low $(0.646 \%)$.

$$
[\text { Tracer }]^{\mathrm{E}}=\left(\frac{\mathrm{R}^{\mathrm{E}}-\mathrm{R}^{\mathrm{B}}}{\mathrm{R}^{\mathrm{B}}}\right) \mathrm{f}_{\text {Tracer }}^{\mathrm{B}}[\text { Metal }]
$$

The expression, $\left[\left(R^{E}-R^{B}\right) / R^{B}\right]$ is the enrichment of the tracer isotope and is often designated as $\Delta$.

The application of equation 10 can be illustrated through an example. Suppose enough ${ }^{25} \mathrm{Mg}$ is added to a $1-\mathrm{mM}$ solution of magnesium to just double the concentration of ${ }^{25} \mathrm{Mg}$. In this example, the ${ }^{25} \mathrm{Mg}$ signal, relative to the internal standard signal, ${ }^{24} \mathrm{Mg}$, will be larger in the enriched sample by a factor of 2 (i.e. $\mathrm{R}^{\mathrm{E}}=2 \mathrm{R}^{\mathrm{B}}$ ). If the test subject had a natural abundance of magnesium initially, $\mathrm{f}_{24}^{\mathrm{B}}$ and $\mathrm{f}_{25}^{\mathrm{B}}$ are 0.7870 and 0.1013 , respectively, as indicated in the appendix Table. The concentration of magnesium in the enriched sample, $[\mathrm{Mg}]^{\mathrm{E}}$, is normally determined by atomic absorption spectrophotometry. The molar concentrations and fractional atomic abundances of the magnesium isotopes in the base and enriched materials are given in Table A. Substituting these values into equation 10 gives the correct tracer concentration of $0.1013 \mathrm{mmol} /$ liter. 